\title{
Filigrane
}

Écoutes psychothérapiques

\section{Argumentaire 2012 : psychanalyse et engagement}

\section{Le comité de rédaction}

Volume 19, numéro 2, automne 2010

URI : https://id.erudit.org/iderudit/1000463ar

DOI : https://doi.org/10.7202/1000463ar

Aller au sommaire du numéro

Éditeur(s)

Revue Santé mentale au Québec

ISSN

1192-1412 (imprimé)

1911-4656 (numérique)

Découvrir la revue

Citer ce document

Le comité de rédaction (2010). Argumentaire 2012 : psychanalyse et engagement. Filigrane, 19(2), 121-122. https://doi.org/10.7202/1000463ar d'utilisation que vous pouvez consulter en ligne.

https://apropos.erudit.org/fr/usagers/politique-dutilisation/ 


\title{
Argumentaire 2012: Psychanalyse et engagement
}

\author{
Le comité de rédaction
}

Pour our célébrer l'entrée de Filigrane dans sa $21^{\mathrm{e}}$ année de publication continue, le comité de rédaction propose à ses lecteurs une réflexion sur le thème de l'ENGAGEMENT.

Il est évident que sans une implication soutenue et les efforts constants de tous ceux qui ont cru à la pertinence d'une revue clinique psychanalytique francophone depuis ses tout débuts, Filigrane n'aurait pas franchi le seuil de sa pleine majorité. Certes les projets de longue haleine et la nécessité de composer avec la durée font partie du quotidien de tout clinicien inscrit d'emblée dans le long cours, à contrecourant des modes et des techniques éphémères, vites conquises et rapidement expédiées. Qu'en est-il des multiples facettes de l'engagement qui seraient susceptibles de questionner notre frilosité mais aussi d'inspirer notre pensée, notre travail psychanalytique en tant que travail de culture (Kulturarbeit)?

La question de la durée nous renvoie à celle de l'engagement clinique: la psychanalyse s'inscrit de plain-pied dans le long terme; le temps nécessaire à l'élaboration, voire à la création d'un espace psychique pour penser ce qui n'a pu l'être, en témoigne de façon convaincante mais aussi rébarbative selon les allégeances. L'analyse interminable pourrait en laisser entrevoir les pièges, mais de toute manière il y a cette offre d'un temps et d'un lieu indéterminés pour parler, perlaborer la souffrance aussi longtemps qu'il le faudra. Pensons aux analystes qui s'engagent à travailler avec des patients psychotiques. Dans ces zones mais pas seulement dans celles-ci, on pourrait même considérer l'engagement du psychanalyste à l'aune de la mélancolie, dès qu'il se trouve confronté à des problématiques «lourdes », où l'archaïque, la régression, les agirs peuvent le pousser jusqu'aux confins de la passion.

Pourtant chacun doit bien moduler son travail selon ses capacités, ses lieux et ses modalités d'engagement. Il faut bien trouver la manière de concilier cet engagement avec les exigences de la neutralité, de la confidentialité mais aussi de la nécessité de préserver son intégrité personnelle. Engagement ne signifie pas passivation. La cure psychanalytique engage le clinicien à son corps défendant, ce que découvrent avec inquiétude sans doute les jeunes cliniciens. L'engagement dans la formation, dans l'analyse personnelle, dans la supervision psychanalytique, dans l'enseignement ou le travail en institution, relève toujours d'un défi improbable, subversif, à contre-courant des visées lénifiantes, et des livres noirs 
qui ne cesseront de vouloir discréditer la psychanalyse. L'engagement dans le maintien d'une psychanalyse vivante est toujours aussi exigeant que du temps de son créateur.

Mais qu'en est-il de l'engagement, côté analysant? À quoi engage une demande d'analyse, de quelle prise en compte de la souffrance psychique s'agit-il ? Reconnaître, vouloir, désirer prospecter une scène interne dont nous savons combien elle peut être terrifiante. Qui veut vraiment s'engager dans une relation où le transfert sera constamment repris, regardé, analysé-diffracté? Il y a bien une «folie » de l'engagement dans cette alliance thérapeutique. Sa durée ne cessera de mettre à l'épreuve la résistance, les coûts financiers, il faut bien en parler, les blessures toujours actuelles qu'on a tenté de faire taire avant d'arriver chez le psychanalyste. Engagement terriblement exigeant et totalement contraire à l'air du temps.

Parler d'engagement c'est aussi parler de l'éthique de la psychanalyse, solitaire, personnelle, mais en tension avec la nécessité d'inscription dans une filiation, voire une institution...

Qui dit engagement, dit mise à l'épreuve de cet engagement dans la cité; dans la pratique, dans la diffusion, dans l'enseignement, voire dans l'application (mot souvent honni) de la psychanalyse. Travail avec des patients financièrement démunis, «adaptation» de la psychanalyse, en la laissant féconder des terrains mouvants et inusités. Engagement dans des débats publics controversés où la vie psychique est mise en danger, mise à mort. Comment pouvons-nous repérer et témoigner de ce qui en chacun de nous fait collusion avec nos propres interdits de penser?

La psychanalyse est porteuse d'un travail de culture et en ce sens, l'engagement du clinicien pose la nécessité de s'interroger sur les rapports entre neutralité, retrait et abstention, indifférence et caution muette.

L'engagement est-il au coeur de la psychanalyse avec son parti pris de recherche de vérité subjective, quel qu'en soit le coût narcissique? À vous de répondre. Cette question nous semble engager... l'avenir même de la psychanalyse. 